CDD: 370.19346

\title{
MODOS DE ATUALIZAR O ENUNCIADO CATASTRÓFICO DO PLANETA TERRA NA REVISTA VEJA'
}

WAYS OF UPDATING PLANET EARTH'S CATASTROPHIC STATEMENT IN VEJA MAGAZINE

MODOS DE ACTUALIZAR EL ENUNCIADO CATASTRÓFICO DEL PLANETA TERRA EN LA REVISTA VEJA

\author{
Bárbara Hees Garré ${ }^{1}$ \\ Paula Corrêa Henning ${ }^{2}$
}

RESUMO: O artigo pretende discutir sobre o modo pelo qual a mídia brasileira, especialmente a revista Veja, tem abordado a problemática ambiental da atualidade. Comumente a mídia enuncia de forma catastrófica e terrorista a eminência de uma hecatombe ecológica e que, muito, provavelmente, o fim da vida no Planeta se aproxima. Os aportes teóricos que tomamos nesta pesquisa são aqueles alinhados aos estudos foucaultianos. Como corpus empírico selecionou-se algumas enunciações da revista Veja, um importante artefato cultural, que subjetiva sujeitos, constitui suas vidas e, especialmente, produz modos de ser e de se comportar frente à problemática ambiental. As análises provocam o leitor a olhar catastrofismo como uma das condições de possibilidade para a emergência da Educação Ambiental no Brasil. A partir de tal discussão buscamos, por meio do material empírico e do campo metodológico desse estudo, dar visibilidade ao que entendemos por atualização do enunciado catastrófico do planeta Terra.

PALAVRAS-ChAVE: Educação ambiental. Mídia. Catastrofismo. Michel Foucault.

ABSTRACT: This article aims to discuss the way the print Brazilian media, specifically Veja magazine, has been talking about today's environmental issues. Commonly media lists catastrophically terrorist and the eminence of an ecological catastrophe and that, very probably, the end of life on Planet approaches. The theoretical contributions we make in this study are those aligned with Foucault studies. As empirical corpus we selected some utterances of Veja magazine, an important cultural artifact, subjective subject that constitutes their lives and, especially, produces ways of being and behaving opposite to environmental issues. The analyses provoke the reader to look at the environmental crisis and catastrophism itself as one of the conditions of possibility for the emergence of environmental education in Brazil. From this discussion we seek, through the empirical material and methodological field of this study, to give visibility to what we understand as the update of the catastrophic statement of Planet Earth.

KEYWORDS: Environmental education. Media. Catastrophism. Michel Foucault.

RESUMEN: El artículo se propone a discutir sobre el modo como los medios brasileños, especialmente la revista Veja, han discutido la problemática ambiental de la actualidad. Comúnmente listas de medios catastróficamente terrorista y la eminencia de una catástrofe ecológica y que, muy probablemente, el final de la vida en los enfoques Planet. Los aportes teóricos que tomamos en esa pesquisa son aquellos arraigados a los estudios foucaultianos. Como corpus empírico hemos seleccionado algunas expresiones de la revista Veja, un importante artefacto cultural, con sujeción subjetiva que constituye su vida y, sobre todo, produce formas de ser y de comportarse frente a las cuestiones ambientales. Los análisis provocan el lector a mirar la crisis ambiental, y el propio catastrofismo, como una de las condiciones de posibilidad para la emergencia de Educación Ambiental

\footnotetext{
${ }^{1}$ Doutoranda do PPG em Educação Ambiental da Universidade Federal do Rio Grande. Professora IFSUL-RioGrandense, câmpus Pelotas. Rio Grande (RS) - Brasil. E-mail: barbaragarre@ gmail.com

${ }^{2}$ Doutora em Educação pela UNISINOS. Professora do Instituto de Educação, do PPGEC e do PPGEA da Universidade Federal do Rio Grande. Rio Grande (RS) - Brasil. E-mail: paula.c.henning@ gmail.com

Recebido em: 11/01/2014 - Aceito em: 04/11/2014.
}

\begin{tabular}{|c|}
\hline ETD - Educ. temat. digit. \\
\hline
\end{tabular}


en Brasil. Desde tal discusión buscamos, a través de material empírico y el campo metodológico de este estudio, dar visibilidad a lo que entendemos por actualización del enunciado catastrófico del Planeta Terra.

PALABRAS CLAVE: Educación ambiental. Medios. Catastrofismo. Michel Foucault.

\section{IDEIAS INICIAIS}

O texto que trazemos aqui problematiza o modo pelo qual comumente a mídia brasileira se refere à problemática ambiental da atualidade. Para esse artigo, nosso corpus discursivo está centrado nas enunciações ${ }^{\mathrm{ii}}$ presentes em reportagens de capa da revista Veja que se referem ao campo de saber da Educação Ambiental (EA), de 2001 a 2012. De um modo geral, em seu discurso, a mídia enuncia de forma catastrófica e emblemática, o quanto estamos em eminência de uma hecatombe ecológica e que, muito provavelmente, nos aproximamos do fim da vida no planeta (GARRÉ, 2012; HENNING, RATTO E GARRÉ, 2010; HENNING, HENNING e GARRÉ, 2013; VIEIRA, 2013). Nossa provocação situa-se em evidenciar que os ditos da revista Veja, atrelados a outros tantos artefatos midiáticos, se constituem como uma atualização discursiva de catástrofe no campo da Educação Ambiental.

Assumimos um conceito de Educação Ambiental pautado a partir dos estudos de Michel Foucault, filósofo francês do século XX. Para Foucault (2004) a educação é um campo produtivo para a fabricação de sujeitos modernos, sendo a escola uma instituição de sequestro que governa nossos corpos e almas. Por meio delas - educação e escola - somos adestrados, disciplinados e produzidos como sujeitos alinhados ao tempo em que vivemos. Pensando no campo de saber aqui colocado sob análise, a Educação Ambiental é entendida por nós como uma potente ferramenta na fabricação de sujeitos preocupados com o futuro do planeta: um sujeito verde (GUIMARÃES, 2012); ou ainda um sujeito ecológico (CARVALHO, 2008). Com isso, sabemos que nosso entendimento de EA desalinha-se com as verdades que habitam esse campo de saber: de que ela - a EA - serve para conscientizar, emancipar e tornar livre o sujeito, sendo este necessariamente um sujeito ecologicamente correto. Queremos deixar claro, desde as primeiras linhas deste texto, que nosso campo teórico entende que somos fabricados e imiscuídos nas tramas culturais, sendo hoje, necessária a constituição de outro sujeito, atravessado pela Educação Ambiental. Não se trata de desconsiderá-la como campo de saber; muito pelo contrário! Trata-se, isto sim, de entendê-la como necessária e produtiva nos dias atuais. É sobre isso que versará este artigo: da potência e produtividade - no sentido foucaultiano do termo - da EA nos mais diferentes lugares, sejam eles de educação formal ou não formal.

A mídia é um desses locais em que se reverberam discursos preocupados com o planeta. Por nos ensinar modos de vida ecológicos, por exemplo, pode ser entendida como espaço que auxilia na proliferação da Educação Ambiental, ensinando-nos como nos comportar e viver diante da crise ambiental que se instala na contemporaneidade. Assim, entendemos que os artefatos midiáticos são potentes na produção de subjetividades e

\begin{tabular}{|c|}
\hline ETD - Educ temat diait \\
\hline
\end{tabular}


constituem nossas vidas. Nesse caso, especialmente, produzem nosso modo de ser e de nos comportarmos frente à problemática ambiental. Afinal, "o planeta está em crise!", "Precisamos Preservar!”, “A vida do planeta está em perigo!”. Estas e tantas outras enunciações já foram por nós apreendidas e já fazem parte de nosso dia a dia, já nos acostumamos com elas, já se tornaram "verdades" aceitas por todos. Tais ditos nos interpelam cotidianamente, quando lemos a revista, assistimos ao filme, ouvimos rock, assumimos as dicas do manual de etiqueta para nosso cotidiano. Por meio da nossa própria cultura, somos interpelados e fazemos algumas escolhas, do mesmo modo interferimos nos processos culturais ao assumirmos determinados posicionamentos e não outros.

Aqui tomamos o conceito de verdade a partir dos estudos de Michel Foucault (1990, 2006). Assim, estamos entendendo a verdade como um efeito discursivo, verdade que é produzida e legitimada dentro de determinada episteme e que vai constituindo as formas de ser e viver na atualidade. O autor entende por verdade "o conjunto de procedimentos que permitem continuamente a cada um pronunciar enunciados que serão considerados verdadeiros" (2006, p. 232-233). Dessa forma, olhamos para a verdade como uma fabricação que se dá a partir da seleção de discursos que colocam alguns ditos no verdadeiro e outros, não.

\begin{abstract}
A verdade é deste mundo; ela é produzida nele graças a múltiplas coerções e nele produz efeitos regulamentados de poder. Cada sociedade tem seu regime de verdade, sua 'política geral' de verdade: isto é, os tipos de discurso que ela acolhe e faz funcionar como verdadeiros; os mecanismos e as instâncias que permitem distinguir os enunciados verdadeiros dos falsos, a maneira como se sancionam uns e outros; as técnicas e os procedimentos que são valorizados para a obtenção da verdade; o estatuto daqueles que têm o encargo de dizer o que funciona como verdadeiro. (FOUCAULT, 1990, p. 12).
\end{abstract}

Seguindo a correnteza foucaultiana, entendemos que nossas escolhas não são totalmente livres, mas são escolhas governadas, direcionadas e reguladas. Aqui, estamos colocando em discussão as escolhas governadas, direcionadas e reguladas, que dizem respeito ao apelo midiático sobre a questão da vida do planeta. Somos sujeitos produzidos por um emaranhado de múltiplas relações, interferências e acontecimentos que direcionam nosso modo de ser, de pensar, de escolher e de "sermos livres".

Nesse sentido, entendemos que não há uma verdade para ser descoberta, desvelada, que está escondida ou por trás do discurso. A verdade, ou as verdades, é fabricada no próprio discurso. Destacamos ainda que para enunciar a verdade é preciso estar autorizado, ter legitimidade discursiva; enfim, não é qualquer um que está apto a falar sobre qualquer coisa. Nas palavras do próprio Foucault $(2009$, p. 9): "Sabe-se bem que não se tem o direito de dizer tudo, que não se pode falar de tudo em qualquer circunstância, que qualquer um, enfim, não pode falar de qualquer coisa". Na atualidade olhamos para a revista Veja como uma mídia potente, que está autorizada a falar a verdade sobre a questão ambiental. O que problematizamos aqui não é a veracidade do discurso reverberado em tal mídia, mas o modo como ele nos produz como sujeitos, bem como o próprio campo ambiental. Assim, Veja é 
autorizada a enunciar um discurso verdadeiro referente à crise ambiental e desse modo tem nos constituído como sujeitos deste tempo em que vivenciamos tal crise.

Quanto ao enunciado catastrófico do planeta Terra, sabemos que ele não é "novo" quando se trata da questão ambiental, pois a própria história da Educação Ambiental, enquanto campo de saber já emerge nesse contexto apocalíptico (LUTZENBERGER, 1977 e MARTINEZ, 2006). Fazemos tal consideração para apontar que hoje o enunciado catastrófico do planeta Terra foi retomado, modificado e atualizado. Parece-nos que existem outras estratégias discursivas em operação e que nos convidam a agir de um modo diferente se compararmos aos discursos das décadas de 1970, 1980 e 1990. O que nosso artigo pretende apontar é em que reside tal atualização a partir das enunciações presentes nas capas da revista Veja em que temos nos debruçado.

\section{UMA CONDiÇão de possibilidade para emergência da eA: O CATASTROFISMO}

Alterações climáticas, desaparecimento de espécies, inundações de água, escassez de alimentos, tremores de terra, enfim, são diferentes fenômenos que vemos acontecer de modo cada vez mais frequente nas últimas décadas. Quando se trata de pensar a questão ambiental talvez sejam essas imagens que primeiro tenhamos lembrança, que primeiro venham ao nosso pensamento. E isto ocorre não só porque vivemos a crise ambiental que se instala na atualidade, mas também porque fomos ensinados a ver e a falar sobre essa crise. Histórias em quadrinhos, livros didáticos, outdoors espalhados pelas cidades e estradas, reportagens de jornais e revistas, filmes, desenhos, documentários, enfim, toda uma série de artefatos culturais nos ensina a olhar e a compreender o meio ambiente e a natureza de determinada forma. Aqui entendemos que os artefatos culturais educam sobre diferentes questões, constituindo e produzindo, afirmando ou negando determinadas identidades, determinados gestos, determinadas posturas.

A própria Educação Ambiental se constitui por uma visão catastrófica e apocalíptica. Ao olharmos sua constituição, identificamos que sua emergência se dá a partir de uma preocupação mundial com as alterações realizadas ao meio ambiente. Dessa forma, a EA se constrói historicamente a partir de uma concepção de problema, de crise, na qual é necessário aliar forças para salvar o planeta. Isso se torna visível quando voltamos nossa atenção para os grandes encontros e conferências mundiais que desencadearam a EA como um campo de saber.

Assim, ao fazermos uma rápida retomada dos importantes encontros que compõe a história da EA, percebemos que ela emerge em um contexto marcado pela crise, pela necessidade de pensar alternativas de melhorar a qualidade de vida das pessoas e do próprio planeta. Em 1972, aconteceu a Conferência de Estocolmo, considerada o marco da EA, na qual o objetivo principal dizia respeito à necessidade de uma educação dirigida para a solução dos problemas ambientais. Em 1975, na Conferência de Belgrado, foi criada a Carta de

\begin{tabular}{l|l|l|l|l|l|l} 
(C) ETD - Educ. temat. digit. & Campinas, SP & v.16 & n.3 & p.426-439 & set./dez. 2014 & ISSN 1676-2592
\end{tabular}


Belgrado que preconizava uma nova ética planetária, erradicando a forme, a pobreza, o analfabetismo, a poluição, a exploração e a dominação humana. Na Conferência Internacional de Tbilisi, realizada em 1977, surgem os objetivos, funções, estratégias, características e recomendações da EA. Foram criadas 41 recomendações que zelam pela união internacional de esforços para o bem comum. Em 1987 ocorre a Conferência de Moscou com o objetivo de avaliar o desenvolvimento da EA desde a Conferência de Tbilisi. Todos esses grandes encontros mundiais, que foram marco na constituição histórica do campo da Educação Ambiental, tiveram como propósito e pauta discutir as problemáticas ambientais e apontar as possíveis soluções - o que confirma que pensar o ambiental, tornou-se importante a partir do momento que isso se tornou um problema a ser resolvido. Assim, a EA emerge como um campo de saber voltado para a crise, a catástrofe, com o objetivo de pensar alternativas para mudar o rumo do que está ocorrendo com o planeta, ou melhor, do que os homens estão fazendo com ele. Desse modo, parece que não há como desvincular a EA de um enunciado catastrófico do planeta Terra.

No Brasil, a Educação Ambiental foi formalmente instituída pela Lei Federal nº 6938, sancionada em 31 de agosto de 1981, quando foi criada a Política Nacional de Meio Ambiente, mas foi na década de 1990, mais especificamente em 1992, com a realização da Eco 92, no Rio de Janeiro, que ela ganhou potência e visibilidade nacionalmente. Naquele cenário chamou a atenção o depoimento realizado pela menina de 12 anos, Severn Suzuki, que ficou mundialmente conhecida. Abaixo, transcrevemos um trecho de sua fala que apontava o contexto calamitoso para o qual a humanidade caminhava.

[...] Todo o dinheiro que precisávamos para vir de tão longe conseguimos por nós mesmos para dizer que vocês, adultos têm que mudar seu modo de agir.

Ao vir aqui hoje, não preciso disfarçar meu objetivo: estou lutando pelo meu futuro. Não ter garantia quanto ao meu futuro não é o mesmo que perder uma eleição ou alguns pontos na bolsa de valores.

Estou aqui para falar em nome das gerações que estão por vir.

Estou aqui para defender as crianças que estão com fome cujos apelos não são ouvidos.

Estou aqui para falar em nome dos incontáveis animais morrendo em todo o planeta porque já não têm mais para onde ir.

Não podemos mais permanecer ignorados.

Hoje tenho medo de tomar sol por causa dos buracos na camada de ozônio.

Tenho medo de respirar esse ar porque não sei que substâncias químicas o estão contaminando. [...] [grifos nossos].

Futuro, medo, crise, contaminação... Seria possível pensar a EA para além de tais questões? Nos materiais em que nos debruçamos para o estudo até o momento parece que não. A EA carrega tais consignas fortemente. Talvez um dos grandes desafios seja o de pensar outras possibilidades para o campo ambiental no século XXI!

Retomando nossa discussão, como vimos rapidamente, o cerne da discussão ambiental sempre foram as questões calamitosas, assim, não há dúvidas de que o enunciado catastrófico do planeta Terra não é novidade quando se trata dessa temática. Para corroborar com essa 
hipótese apontamos ainda uma importante contribuição de José Lutzenberger (1977), que se dedicou fortemente à questão ecológica. Em sua obra Fim do Futuro? Manifesto Ecológico Brasileiro, o autor aponta a urgência de ações para resolver a problemática ecológica e do quanto essas não podem mais ser postergadas.

\begin{abstract}
Somente uma transição rápida a atitudes fundamentalmente novas, atitudes de respeito e integração ecológica, poderão ainda evitar o desastre. Encontramo-nos num divisor de eras. Nossa época encontrará na História, se dermos chance à História, como limiar de uma nova idade. A qualidade de vida nesta nova idade dependerá de nosso comportamento atual e das atitudes que soubermos inculcar na juventude. (LUTZENBERGER, 1977, p. 9) [grifos nossos].
\end{abstract}

A defesa de Lutzenberger é por uma necessária conscientização de que o futuro depende de nós! Do quanto é necessário que façamos algo, que mudemos nossas atitudes para com o ambiente. Fica evidente que se caso não tomarmos tais providências, rumo à mudança, algo poderá acontecer e colocar o futuro da humanidade em risco! Em plena década de 1970 o autor já chamava a atenção para a crise ecológica que abalava e de quanto o homem em sua busca pelo domínio de todas as coisas destruiu e continuava a destruir o mundo natural!

\footnotetext{
Quando nos empolgamos com nosso fabuloso poderio tecnológico e nos orgulhamos do "domínio da natureza", nosso entusiasmo pueril nos torna cegos diante dos verdadeiros custos das modernas tecnologias e não nos permite ver nossa total incapacidade de repor, com a mesma facilidade, o que destruímos. A motosserra e o trator que em minutos derrubam o gigante milenar nos parecem um progresso extasiante, mas nos fazem esquecer que não há e nunca haverá tecnologia capaz de repor no mesmo lugar outro gigante em menos tempo que o que leva uma árvore milenar para formar-se. (LUTZENBERGER, 1977, p. 14) [grifo do autor].
}

O "Manifesto Ecológico" - como comumente essa obra de Lutzenberger é conhecida - denuncia agressões cometidas pelos homens à natureza por muitos e muitos anos. Fala sobre a forma irresponsável e desleixada de utilização dos recursos naturais. Coloca ainda a questão do crescimento demográfico e do quanto ele deverá ser contido. $\mathrm{O}$ autor diz que não tem uma receita para solucionar a crise ecológica, mas que indica algumas pistas e talvez a mais importante delas seja a de que a mudança é urgente e necessária, porém deveríamos estar dispostos a fazermos alguns sacrifícios.

Nosso propósito nesta seção foi apresentar, de modo geral, que o enunciado catastrófico do planeta Terra é marca no campo ambiental. A EA emerge em um cenário crítico, problemático, em que o mundo está com seus olhares voltados para tentar resolver ou, pelo menos, minimizar os efeitos da crise instalada e vivida mundialmente. Nossa tentativa foi deixar evidente tal cenário que se configurou e de como a EA foi se constituindo atravessada neste contexto histórico.

Ao problematizarmos o enunciado catastrófico do planeta Terra, proliferado em alguns artefatos da mídia brasileira, identificamos sua reativação e atualização na contemporaneidade. É justamente essa atualização, em pleno século XXI, que gostaríamos de problematizar na seção a seguir. Para este artigo, debruçamo-nos nas reportagens de capa da

\begin{tabular}{l|l|l|l|l|l|l} 
(C) ETD-Educ. temat. digit. & Campinas, SP & v.16 & n.3 & p.426-439 & set./dez. 2014 & ISSN 1676-2592
\end{tabular}


revista Veja que tratam do campo ambiental. Vale lembrar, como nos ensina Foucault: "O novo não está no que é dito, mas no acontecimento de sua volta”. (2009, p. 26).

\section{A ATUALIZAÇÃO dO CATASTROFISMO NA EA CONTEMPORÂNEA}

Nesta seção nos provocamos a problematizar de que modo a revista Veja retoma o enunciado catastrófico do planeta Terra e o atualiza atendendo a certas exigências de nosso tempo. Como já apresentamos na seção anterior, o catastrofismo não é novidade quando se trata de falar sobre a EA. Porém, na atualidade, principalmente desde 2001, tal reverberação vem sendo produzida discursivamente de um modo diferente. Assim, para esta empreitada selecionamos algumas reportagens de capa da revista Veja que apresentam enunciações potentes que versam sobre a temática em discussão.

Utilizamos neste trabalho a ferramenta analítica de enunciado e aqui vale uma rápida retomada do que estamos entendo por esse conceito e de que modo operamos com ele nos materiais em estudo. Na correnteza dos estudos de Michel Foucault (2002), entendemos o enunciado como uma partícula do discurso. Desse modo, tomamos o enunciado catastrófico do planeta Terra como uma partícula do discurso de Crise Ambiental que se liga a outros enunciados de seu tempo, em uma mesma formação discursiva.

Segundo o autor, o enunciado está na ordem do discurso aceito como verdadeiro e legítimo em nossa sociedade. Para se atualizar precisa ser reativado e transmitido. $\mathrm{O}$ enunciado se modifica conforme o momento histórico, social, cultural em que é ativado. Assim, conforme as tramas, as redes discursivas com que se relaciona ou se apoia, o enunciado pode se modificar.

\footnotetext{
Essa materialidade repetível que caracteriza a função enunciativa faz aparecer o enunciado como um objeto específico e paradoxal, mas também, como um objeto entre os que os homens produzem, manipulam, utilizam, transformam, trocam, combinam, recompõem, eventualmente destroem. Ao invés de ser uma coisa dita de forma definitiva - e perdida no passado como a decisão de uma batalha, uma catástrofe geológica ou a morte de um rei - o enunciado, ao mesmo tempo em que surge em sua materialidade, aparece com um status, entra em redes, se coloca em campos de utilização, se oferece a transferências e a modificações possíveis, se integra em operações e em estratégias onde sua identidade se mantém ou se apaga. Assim, o enunciado circula, serve, se esquiva, permite ou impede a realização de um desejo, é dócil ou rebelde a interesses, entra na ordem das contestações e das lutas, torna-se tema de apropriação ou de rivalidade. (FOUCAULT, 2002, p. 121).
}

Descrever o enunciado é estar atento a examinar a função que exerce e que dá sentido ao discurso. Aqui examinaremos o enunciado catastrófico do planeta Terra, entendendo que ele é da ordem da produtividade e que é potente para esse campo de saber, como já indicamos na seção anterior.

Lutzenberger (1977) já anunciava a proximidade de uma "calamidade global", contestava o consumismo exacerbado, fazia duras criticas à ciência e ao desenvolvimento

\begin{tabular}{l|l|l|l|l|l|l} 
(C) ETD - Educ. temat. digit. & Campinas, SP & v.16 & n.3 & p.426-439 & set./dez. 2014 & ISSN 1676-2592
\end{tabular}


tecnológico, enfim, realizava fortes contestações à forma que a sociedade estava se comportando e agindo frente à crise ecológica.

Em pleno século XXI as capas da revista Veja, a revista com maior número de exemplares distribuídos em nosso país, trazem como destaque:

\section{O Planeta Pede Socorro}

Aquecimento da atmosfera, florestas destruídas, escassez de água limpa, derretimento das geleiras, extinção de animais, ... Ah, tem mais: uma nuvem de poluentes cobre metade da Ásia, onde vive um quinto da humanidade (Veja, reportagem de capa, agosto de 2002).

\section{Salvar a Terra}

Consciência ambiental: filho único; camiseta de fibra reciclada; sacola de fibra natural; fralda de pano; alimentos orgânicos; cantil (para evitar garrafas pet); calça de algodão orgânico feita à mão; bicicleta 0 de $\mathrm{CO}^{2}$; sandálias com lona de pneu reciclado (Veja, reportagem de capa, outubro de 2007).

\section{Estamos Devorando o Planeta}

Água, carne, peixe: o mundo já consome mais do que a Terra pode oferecer. A esperança na nova Revolução Verde (Veja, reportagem de capa, dezembro de 2009)

Aqui entendemos que há uma reativação e atualização do enunciado catastrófico do planeta Terra. De certo modo a revista Veja enuncia e alerta sobre a catástrofe "O planeta pede socorro"; "Salvar a Terra"; "Estamos devorando o planeta". O título da reportagem já é emblemático e já nos interpela, somos convidados a olhar, ler e entender que catástrofe afinal de contas é essa? Por que o planeta pede socorro? O que estamos fazendo com o planeta? Medo, culpa, salvação! E nesse jogo de forças e disputas travado entre nós, indivíduos já subjetivados pelo discurso do "ecologicamente correto", acabamos persuadidos a participar dessa rede discursiva em prol do planeta! Desse modo a revista Veja se constitui como mensageira da catástrofe e ao realizar tal tarefa nos indica de que modo devemos agir frente a essa problemática. O que visualizamos como possibilidade de atualização em tais enunciações reside justamente em indicar maneiras corretas de agirmos, nos comportarmos, de consumirmos como sujeitos preocupados com o meio ambiente e com a vida do planeta.

Não basta que sejamos interpelados pelo medo da catástrofe; o objetivo é sim que tenhamos medo do que pode acontecer e que, frente a isso, tomemos uma atitude - uma atitude responsável. Nesse sentido, entendemos que o consumo consciente é uma possibilidade forte de atualização discursiva do enunciado catastrófico do planeta Terra na revista Veja. Os excertos abaixo foram extraídos das reportagens de capa citadas anteriormente e dão visibilidade a tal entendimento:

Carros Elétricos e Híbridos - Esses veículos emitem até 30\% menos CO2, mas custam até $25 \%$ mais que seus rivais compactos e poluidores. Subsidiá-los é lucro para qualquer metrópole.

Redução: um carro de passeio joga 2 toneladas de carbono por ano na atmosfera, valor igual à quantidade capturada por 170 árvores durante dez anos. (2009, p. 136) 
Consumir menos - Uma lâmpada feita com os modernos LEDs (sigla em inglês para Light Emitting Diode) emite a mesma quantidade de luz de uma lâmpada incandescente tradicional usando apenas $25 \%$ de energia. Além disso, sua vida útil é estimada em 50000 horas, contra apenas 1000 horas das concorrentes. Mas ela ainda custa até vinte vezes mais do que as lâmpadas comuns. (2009, p. 137)

Casa engajada - Entre os ambientalistas dispostos a salvar o planeta sem abrir mão do conforto, uma opção frequente são as casas inteligentes, com painéis solares para gerar energia e mecanismos para a coleta e o reaproveitamento da água da chuva. Por enquanto, construir esse tipo de casa custa caro. (2007, p. 93)

Para manter a consciência limpa com relação á poluição do planeta, a solução mais popular no momento é tomar medidas simples como trocar as sacolas plásticas pela de pano e evitar o consumo de carne - a pecuária é responsável por $18 \%$ da emissão de gases do efeito estufa. (2007, p. 93)

As enunciações anteriores evidenciam o quanto os sujeitos são acionados a agir, a consumir conscientemente e engajarem-se a favor da problemática ambiental, pois ela é planetária. O que questionamos aqui é o modo pelo qual essa trama discursiva nos interpela, nos molda e nos constitui como sujeitos. Na atualidade, a crise ambiental intensifica-se cada vez mais. Somos surpreendidos diariamente por desastres naturais dos mais imprevisíveis possíveis, a própria ciência que tinha tantas convicções não dá mais conta, de forma outrora tão veemente, de responder ao que nos acomete. Então, nossa provocação se situa em pensar de que modo estamos vivendo este tempo ou e de que modo estamos sendo posicionados a viver este tempo? Que escolhas fazemos e de que modo somos conduzidos a elas? Quando lemos a revista, assistimos ao filme, escutamos música, vamos ao supermercado, que escolhas estamos fazendo?

"Sociedade de Consumidores", "Sociedade de Hiperconsumo", "Consumo Consciente", "Consumo Sustentável", de que modo tais expressões se cruzam? Na atualidade é possível pensarmos as questões ambientais sem questionarmos os atravessamentos da política do consumo? Entendemos que o ambiental e em especial o enunciado catastrófico do planeta Terra, aqui em discussão, está cada vez mais emaranhado nessa onda consumista, que constitui nossos modos de vida na contemporaneidade.

Bauman $(2001,2008)$ nos auxilia a pensar na "sociedade de consumidores" na forma como a cultura do consumo se espalhou e invadiu todas as esferas do globo terrestre. Cada vez mais somos seduzidos pelo desejo de consumir. Somos, a todo o momento, cutucados, incitados, provocados a consumir, a desejar algo. O consumo é marca forte da sociedade líquida moderna e assim como ela, assume características de fluidez, de volatilidade. Parece que há sempre algo novo para ser consumido, adquirido. Nunca estamos satisfeitos!

Nesse sentido, Marisa Vorraber Costa, ao problematizar a cultura consumista na sociedade de consumidores, destaca:

[...] Aprendemos a renascer: novas carreiras, novas identidades, novos afetos; e a recomeçar incansavelmente. De fato, a vida na sociedade de consumidores pouco 
tem a ver com aquisição e posse. O que a distingue, sobretudo, é a indispensável condição de "estar em movimento". Somos inapelavelmente incitados a prosseguir; permanentemente pressionados a querer mais, ser mais, experimentar mais. (...) A própria sociedade de consumidores estimula a antecipação do descarte e premia a reposição constante. O telefone celular (ou a Barbie, o computador, o par de tênis, a namorada, o emprego) recém adquirido pode ser substituído praticamente sem custos, ou com mínimo custo, por outro mais novo, aperfeiçoado ou conveniente. Leve o velho à loja, e ela se encarregará de livrá-lo desse incômodo do passado (COSTA, 2009, p. 36-37).

$\mathrm{Na}$ correnteza desses autores, entendemos que na atualidade há uma obsessão, uma compulsão pelo consumo, tornando-se marca registrada da vida moderna. É notório o quanto o consumo se constitui como eixo organizador das sociedades do presente, nas quais se articulam as formas de ser e de viver dos sujeitos, produzindo e inventando suas/nossas subjetividades.

$\mathrm{Na}$ sociedade de consumidores, cada sujeito está engajado em práticas de empreendedorismo dedicadas a transformar a si próprio em uma mercadoria vendável, consumível. O corpo do sujeito tem sido alvo de inúmeros investimentos, tornando-se passível de inúmeras transformações, ou seja, modificações que o transformam, marcam, diferenciam. Existe uma verdadeira indústria em torno da produção e desejo sobre esses corpos. Moda, estética, cirurgias, adereços e tatuagens são algumas das possíveis intervenções que demonstram o quanto o corpo vem sendo investido, ressignificado e investigado. Investir nas imagens corporais para ser/ter um corpo inteiramente pronto para ser filmado, fabricado, fotografado, visto e admirado. Em todos os âmbitos podemos perceber o quanto mostrar a si mesmo tem se tornado algo que constitui e que marca a sociedade contemporânea. A imagem é central para a nossa produção, para mostrar como somos, quais os nossos pertencimentos, e fazer isso é se disponibilizar cada vez mais ao consumo.

Gilles Lipovetsky trata da "sociedade de hiperconsumo" e a caracteriza pela busca da felicidade individual, conforme as palavras do próprio autor:

\footnotetext{
A civilização do bem-estar consumista constituiu o grande coveiro histórico da ideologia gloriosa do dever. Ao longo da segunda metade do século, a lógica do consumo de massas dissolveu o universo das homilias moralizadoras, erradicou os imperativos rigoristas e engendrou uma cultura onde a felicidade se impõe como mandamento moral, os prazeres ao proibido, a sedução à obrigação. [...] O culto da felicidade em massa veio generalizar a legitimidade dos prazeres e contribuir para a promoção da febre da autonomia individual (LIPOVETSKY, 2004; p. 60).
}

No entendimento do autor vivemos uma era do consumo para nós mesmos, buscando uma satisfação cada vez mais individual. É uma busca individualista "o consumo do indivíduo 'para si' suplantou o consumo 'para o outro"”. (LIPOVETSKY 2007, p. 36) [grifos do autor]. Na mesma correnteza de Lipovetsky, Bauman defende que a "sociedade de consumidores", "[...] representa o tipo de sociedade que promove, encoraja ou reforça a escolha de um estilo de vida e uma estratégia existencial consumista" (2008, p. 71). 
Desse modo, vamos nos constituindo em consumidores ativos e participantes dessa "sociedade de consumidores" ou "sociedade de hiperconsumo". No que se refere à questão ambiental, entendemos que há uma busca incessante em incitar outro modo de consumir, mais consciente, mais alinhado com a sustentabilidade do planeta. Nessa busca pela sustentabilidade se produz e subjetiva um determinado tipo de sujeito, preocupado com o futuro deste planeta e com a qualidade de vida das próximas gerações. Desse modo, evidenciamos o quanto o discurso do ecologicamente correto e do consumo consciente está atrelado também a um consumo desenfreado, ou seja, há uma propagação de produtos, formas de ser e de viver em consonância com um mundo mais sustentável.

\begin{abstract}
As redes de mercantilização e consumo investem maciçamente no discurso da responsabilidade social e das políticas de inclusão. A compra de mercadorias é revestida de uma aura de ato político, em que o consumo acontece não apenas para mostrar o que se tem e o que se pode, mas também para ajudar o próximo. Eis que surgem camisetas, pulseiras, bonés e bandas para cabelo que anunciam seu engajamento na luta contra o câncer infantil, de mama, a AIDS, o fumo, a discriminação aos gays, a exploração sexual de meninas. Em cada uma dessas campanhas, de certa forma, também se consome o "outro". (COSTA, 2009, p. 31) [grifo da autora].
\end{abstract}

Entendemos que a problemática ambiental se insere nesses discursos de responsabilidade social como bem descreve Marisa Vorraber Costa no excerto anterior. É a partir desse convite, nos convocando a assumir nossas responsabilidades frente às catástrofes ecológicas que a mídia vai nos persuadindo e nos capturando a participar da cultura consumista, fazendo algo em prol do planeta Terra. Nossas atitudes, na sociedade de consumidores, vão além de economizar água, reciclar o lixo e plantar uma árvore. É preciso bem mais do que isso! É preciso apostar na compra de produtos que colaborem com essa grande campanha mundial para que a vida no Planeta Terra não se esgote. Para tanto estão aí as ecobags, ecoclothes, ecohouses, móveis ecowood e tantos outros produtos para serem consumidos em nome do medo, instalado em nossas vidas por meio do enunciado catastrófico do planeta Terra tão em evidência na revista Veja. Abaixo segue mais um conjunto de enunciações que dão visibilidade ao que estamos tratando aqui:

Para onde vamos com nossas agressões ao Planeta? O pessimismo da resposta varia, mas há um consenso: a hora de agir é já. (2005, p. 84)

Como uma praga apocalíptica, as mudanças climáticas já semeiam furacões, incêndios florestais, enchentes e secas com tal intensidade que ninguém mais pode se considerar a salvo de ser diretamente atingido por suas consequências. (2006, p. 74)

Diante da imposição de combater o aquecimento global, as ações individuais nessa direção se tornam uma mania. Todo mundo quer fazer sua parte para salvar o planeta, ou pelo menos manter a consciência limpa de que não está ajudando a piorar a situação. Para isso tanto vale usar roupas de algodão orgânico quanto comprar apenas produtos que tenham sido produzidos em regiões próximas - dessa forma, não se precisou esfumaçar mais a atmosfera ao transportá-los. (2007, p. 92) 
Desse modo, entendemos que o consumo consciente, ou consumo sustentável, que tem como investimento o sujeito preocupado com o futuro do planeta Terra, é uma das possibilidades potentes de atualização discursiva do enunciado catastrófico do planeta Terra no material aqui em discussão. Pois a atualização discursiva de tal enunciado reside justamente em indicar o modo como os sujeitos devem se conduzir diante da catástrofe e, nesse caso, uma das formas é consumir de modo correto, adquirindo produtos sustentáveis. Consumir conscientemente, em prol do planeta Terra! Essa é a consigna da atualidade!

\section{CONSIDERAÇ̃̃ES FINAIS}

Parece-nos que os artefatos midiáticos, especialmente a revista Veja, tem nos ajustado a certo modo de vida, a certo modo de viver, de modo a nos tornarmos sujeitos diante da crise ambiental. Nossas posições e entendimentos estão naturalizados de tal maneira que se torna difícil rompermos com este entendimento: de ambiental atrelado à crise, à catástrofe, ao medo, ao consumo consciente. Consumir de modo sustentável, de modo consciente, causando menos impacto ao meio ambiente - estaria aqui a possibilidade de salvar a Terra? Entendemos que o direcionamento de nosso modo de agir tem sido uma das estratégias utilizadas pela revista Veja para atualizar o enunciado catastrófico do planeta Terra. Como não participar dessa onda verde em prol da vida do planeta? Como não consumir produtos que reduzam os impactos ambientais? Como ficar indiferente ao quadro calamitoso que está se desenhando? Como não agirmos, não fazermos a nossa parte? As enunciações tratadas nas reportagens em análise nos apresentam a situação que temos para enfrentar. Precisamos intervir logo, cada um fazendo a sua parte, em benefício da vida futura.

Nossa provocação final é no sentido de nos colocarmos a pensar em tais ditos e de que forma eles produzem nossas vidas públicas e privadas. Será que ao atendermos ao convite, ao chamamento midiático, comprando uma lâmpada de led, uma sandália de lona de pneu reciclado, construindo uma casa engajada ou utilizando uma sacola de pano estamos fazendo por entender que é necessária outra forma de nos relacionarmos com o ambiente, ou fizemos por medo e culpa? Fazemos porque somos subjetivados ao "ecologicamente correto"? Será que com tais chamamentos apocalípticos a revista Veja nos convida a pensar nas relações sociais, culturais e ambientais que estamos produzindo? Pensar em tais questões é o que tem movido nossas pesquisas.

\section{REFERÊNCIAS}

A TERRA no Limite. In: Veja, São Paulo, ed. 1926, 12 de out. 2005.

BAUMAN, Zigmunt. Modernidade líquida. Rio de Janeiro: Ed. Jorge Zahar, 2001.

BAUMAN, Zigmunt. Vida para consumo: a transformação da pessoas em mercadoria. Rio de Janeiro, RJ: Ed. Zahar, 2008. 
CARVALHO, Isabel Cristina Moura de. Educação ambiental: a formação do sujeito ecológico. 4. ed. São Paulo: Cortez, 2008.

COSTA, Marisa Vorraber. O consumismo na sociedade de consumidores. In: COSTA, Marisa Vorraber (Org.). A educação na cultura da mídia e do consumo. Rio de Janeiro, RJ: Ed. Lamparina, 2009.

ESTAMOS devorando o planeta. In: Veja, São Paulo, ed. 2143, 16 de dez. 2009.

FOUCAULT, Michel. Microfísica do poder. 17.ed. Rio de Janeiro, RJ: Graal, 1990.

FOUCAULT, Michel. A arqueologia do saber. 6.ed. Rio de Janeiro, RJ: Forense Universitária, 2002.

FOUCAULT, Michel. Ditos e escritos IV: estratégia, poder-saber. 2.ed. Rio de Janeiro, RJ: Forense Universitária, 2006.

FOUCAULT, Michel. A ordem do discurso. 18.ed. São Paulo, SP: Edições Loyola, 2009.

GARRÉ, Bárbara Hees. A produção discursiva da educação ambiental na revista Veja: modos de constituir-se sujeito na atualidade. 2012. Projeto de qualificação (Doutorado) Programa de pós-graduação em Educação Ambiental da Universidade Federal do Rio Grande, Rio Grande, 2012.

GUIMARÃES, Leandro Belinaso. Notas sobre o dispositivo da sustentabilidade e a formação de sujeitos verdes. In: SARAIVA, Karla; MARCELLO, Fabiana de Amorim (Org.). Estudos culturais e educação: desafios atuais. Canoas: ULBRA, 2012. p.219-232. v.1.

HENNING, Paula Corrêa; RATTO, Cléber; GARRÉ, Bárbara Hees. Educação ambiental, mídia e biopoder. In: REUNIÃO ANUAL DA ANPED, 33., 2010, Caxambu. Anais da... Rio de Janeiro, RJ: ANEPD, 2010.

HENNING, Paula Corrêa; HENNING, Clarissa Corrêa; GARRÉ, Bárbara Hees. Educação ambiental e cinema: produções discursivas em tempos líquidos. In: GUIMARÃES, Leandro Belinaso; GUIDO, Lucia Estevinho; SCARELI, Giovana (Org.). Cinema, educação e ambiente. Uberlândia: EDUFU, 2013.

LIPOVETSKY, Gilles. O crepúsculo do Dever: a ética indolor dos novos tempos democráticos. Lisboa: Dom Quixote, 2004.

LIPOVETSKY, Gilles. A felicidade paradoxal: ensaio dobre a sociedade de hiperconsumo. Lisboa: Edições 70, 2007.

LUTZENBERGER, José A. Fim do futuro?: manifesto ecológico brasileiro. Porto Alegre: Ed. Movimento, 1977.

MARTINEZ, Paulo Henrique. História ambiental no Brasil: pesquisa e ensino. São Paulo, SP: Cortez, 2006. 
O PLANETA pede socorro. Veja, São Paulo, ed. 1765, 21 ago. 2002.

OS SINAIS do apocalipse. Veja, São Paulo, ed. 1961, 21 jun. 2006.

SALVAR a Terra. Veja, São Paulo, ed. 2031, 24 out. 2007.

VIEIRA, Virgínia Tavares. O discurso da crise ambiental nas letras de rock and roll: modos de ser sujeitos em tempos contemporâneos. 2013. Dissertação (Mestrado) - Programa de pós-graduação em Educação Ambiental da Universidade Federal do Rio Grande, Rio Grande, 2013.

Como citar este documento:

GARRÉ, Bárbara Hees; HENNING, Paula Corrêa. Modos de atualizar o eunciado catastrófico do Planeta Terra na revista Veja. ETD - Educação Temática Digital, Campinas, SP, v. 16, n. 3, p.426-439, set./dez. 2014. ISSN 1676-2592. Disponível em: <http://www.fe.unicamp.br/revistas/ged/etd/article/view/6792>. Acesso em: 23 dez. 2014.

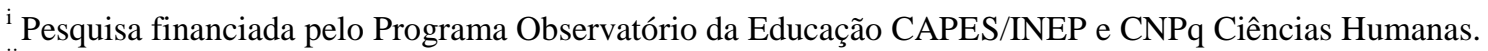
ii "Diremos que há enunciação cada vez que um conjunto de signos for emitido" (FOUCAULT, 2002, p. 116). As enunciações dão visibilidade e sentido ao enunciado.
} 